\title{
Dinâmica da infecção pelo vírus da leucemia bovina em rebanho leiteiro
}

Fabrício Dias Torres ${ }^{[a]}$, Matheus Piovesan ${ }^{[b]}$, Natália Meirelles Sobreira ${ }^{[a]}$, Viviani Gomes ${ }^{[a]}$

\footnotetext{
[a] Faculdade de Medicina Veterinária e Zootecnia, Universidade de São Paulo (USP), São Paulo, SP, Brasil

${ }^{[b]}$ Laboratório Axys Análises, Porto Alegre, RS, Brasil
}

*Autor correspondente

e-mail: torres@axysanalises.com.br

\section{Resumo}

0 vírus da leucemia bovina (BLV), agente causador da leucose enzoótica bovina (LEB), apresenta alta prevalência em rebanhos produtores de leite devido ao nível de intensificação e lotação desse sistema de produção. Por ser um retrovírus, o animal infectado permanecerá portador do agente por toda a vida. A transmissão da LEB pode ocorrer tanto por via vertical (mãe para a cria) como por via horizontal. A transmissão horizontal ocorre por manejo (luvas de palpação e agulhas) ou por vetores biológicos, como insetos hematófagos. 0 objetivo desse trabalho foi avaliar a soroprevalência de anticorpos específicos (ACs) contra a BLV, além da identificação de fatores de risco associados com a transmissão do agente. Foram colhidas 100 amostras de soro em um rebanho de alta produção composto por um total de 745 animais. A amostragem foi proporcional às categorias da propriedade e estratificadas por idade (meses) - 0 - 4, 4 - 12, 12 - 18, 18 - 24, 24 - 36, 36 - 48, mais de 60 meses -, e as amostras foram testadas com ensaio imunoezimático de bloqueio comercial (ELISA INgezim BLV Compac $2.0^{\circledR}$ ). A prevalência geral foi de 43\% (43/100). A análise por categoria apresentou $100 \%$ de positivos entre 0 a 4 meses (5/5), 10\% entre 4 a 12 meses (3/30), 27\% entre 12 a 18 meses (3/11), 43\% entre 18 a 24 meses (3/7), 46\% entre 24 a 36 meses (6/13), 60\% entre 36 a 48 meses (9/15) e 82\% em animais com idade acima de 60 meses (9/11). A alta soroprevalência em animais com faixa etária entre 0 e 4 meses pode ser justificada pela transferência de anticorpos colostrais, considerando queda na taxa de soropositivos entre 4 a 12 meses de idade. Este resultado sugere uma baixa taxa de transmissão vertical quando comparado à transmissão horizontal. Na propriedade, os animais começam a ser manejados para fins de reprodução a partir dos 12 meses de idade. Nessa fase começam as avaliações, o uso de biotecnologias da reprodução (espéculo, palpação retal e ultrassonografias). A partir dessa idade observa-se um rápido e elevado aumento no número de animais soropositivos. A fazenda na 
qual foi realizado este levantamento utiliza luvas e agulhas descartáveis sem reuso posterior; entretanto, a transmissão iatrogênica, como a sonda ultrassonográfica transretal, não pode ser descartada, considerandose que esta não é lavada e esterilizada entre animais. A soroprevalência aumentou gradualmente de acordo com a idade e o tempo em produção dos animais. Nos animais acima dos 60 meses a soroprevalência foi de $82 \%$, reforçando a importância no combate da transmissão horizontal do agente. Como a LEB é uma doença de caráter subclínico e com impacto em produtividade, torna-se importante conhecer os principais fatores de risco para o estabelecimento de protocolos estratégicos para a prevenção da infecção pelo BLV. 